\title{
OS SENTIDOS DOS "NÓS" E DOS "ELES" NOS DISCURSOS DE MIGRANTES BRASILEIROS NO EXTERIOR
}

\author{
Thaís Valim Ramos ${ }^{82}$
}

RESUMO: Este trabalho tem como objetivo apresentar os diferentes sentidos atribuídos aos pronomes "nós" e "eles" nos discursos de brasileiros que estão morando no exterior. Estes sentidos não se dirigem ao mesmo referente dependendo da posição que os sujeitos ocupam em uma formação discursiva. Assim, um sujeito pode ocupar um lugar em um momento e ser excluído ou se excluir em outro. A justificativa deste trabalho está no fato de que por meio do uso destes pronomes e seus efeitos de sentido podemos observar as relações de poder que se estabelecem entre os "nacionais" e os "estrangeiros" num momento em que estamos vivendo um grande movimento migratório de sujeitos a nível mundial. Nestas relações, ora o sujeito em seu lugar de brasileiro ocupa uma posição inferior, quando em países considerados desenvolvidos; ora ocupa uma posição superior, quando em países periféricos. Nos apoiaremos nos pressupostos teóricos da análise do discurso pecheutiana para fazer as análises dos discursos que compõem o arquivo deste trabalho.

Palavras Chave: nós; eles; efeito de sentido; imigrante; estrangeiro.

ABSTRACT: This study aims to present the different meanings attributed to the pronouns "we" and "they" in the discourses of Brazilians who are living abroad. These meanings do not address the same referent depending on the position that subjects occupy in a discursive formation, so a subject can occupy one place at a time and be excluded or exclude himself in another. The justification for this work lies in the fact that through the use of these pronouns and their effects of meaning we can observe the relation of power that are established between the "nationals" and the "foreigners" in a time when we are experiencing a great migratory movement of subjects worldwide. In these relations the subject in his place of Brazilian occupies a lower position, when in countries considered developed; but occupies a higher position when in peripheral countries. We will rely on the theoretical support of the analysis of discourse

${ }^{82}$ Doutora em Letras na Universidade Federal do Rio Grande do Sul. 
pecheutiana to make the analyzes of the discourses that are part of the archive of this work.

Key words: we; they; meaning effect; immigrant; foreigner.

\section{Introdução}

Este artigo faz parte de um estudo maior, cujo objetivo é analisar pistas nos discursos de brasileiros que vivem no exterior que indiciem modos de subjetivação, permitindo-nos lançar um gesto de interpretação sobre este sujeito que se insere em outra língua e outra cultura, uma vez que o sujeito se constitui pela ordem do simbólico, e é pelo significante que ele se define. Para constituição do arquivo desta pesquisa, coletei nomes e e-mails de brasileiros que estavam residindo no exterior há mais de um ano através de uma rede de amigos e conhecidos, que buscavam informações com outras pessoas a fim de contribuir com a pesquisa. Os entrevistados também indicavam outros brasileiros que, da mesma forma, poderiam contribuir com este estudo. Após o convite e explicações sobre o trabalho, assim como o aceite dos participantes, as entrevistas foram marcadas e realizadas por meio do Skype ${ }^{83}$.

Neste artigo buscamos os sentidos atribuídos aos pronomes "nós" e "eles" nos discursos de brasileiros que estão residindo no exterior. Os sentidos atribuídos ao "nós" e ao "eles" se dão pela necessidade de marcar a diferença, a qual está ligada às relações de poder. Essas marcas de poder estão presentes nas fronteiras estabelecidas entre "nós" e "eles", no poder de incluir e excluir, de dizer quem pertence e quem não pertence, quem é bom e quem é mau, quem é desenvolvido e quem é primitivo. A definição do aceitável e do desejável depende do que é considerado normal ou anormal, do rejeitável para existir e criar laços imaginários que funcionam como identidades nacionais e que Anderson (2008) chama de "comunidades imaginadas". Dessa forma, a divisão social entre "nós" e "eles" sugere classificar, hierarquizar para, então, incluir ou excluir, levando os sujeitos a assumirem suas posições-sujeito.

Em um contexto sócio-político e histórico, cada formação social constrói um conjunto de classificações que permite que seus membros se identifiquem entre si e identifiquem os outros. Os sentidos que fazem uma nação constituem-se sócio-historicamente sob uma forma estabilizada que produz o sujeito, dando-lhe o que ver, fazer, temer, esperar. E, através

83 Skype é um software que permite comunicação pela Internet através de conexões de voz e vídeo 
Os sentidos dos "nós" e dos "eles" nos discursos de migrantes brasileiros no exterior | 201 dessa via, o sujeito reconhece a si mesmo e ao outro, determinando quem faz e quem não faz parte de um país, delimitado por fronteiras. É este limite territorial que define quem está "dentro" e quem está "fora". Bauman (2012) afirma que "ter uma identidade" parece ser uma das necessidades mais universais, embora não considere como uma necessidade universal, mas historicamente associada à fragilidade do sujeito.

A identidade social, o "nós", inclui o "eu", precário e inseguro, abrigando-o e dando-lhe segurança sobre o "eles", os estranhos, adversários. O autor diz que parecemos participar da busca do que Michel Morineau chamou de "la doucer d'etre inclu" ${ }^{44}$ e cita Morineau dizendo que:

Por si mesma, em certo sentido, essa expressão diz tudo: corresponde a um desejo básico - o de pertencer, fazer parte de um grupo, ser recebido por outro ou por outros, ser aceito, ser preservado, saber que tem apoio, aliados. [...] Ainda mais importante que todas essas satisfações específicas, obtidas uma a uma, em separado, é aquele sentimento subjacente e profundo, sobretudo o de ter a identidade pessoal endossada, confirmada, aceita por muitos - o sentimento de que se obteve uma segunda identidade, agora uma identidade social (BAUMAN, 2012, p. 46).

O "nós" precisa ser poderoso e, para tanto, requer a ordem social, que cria a sede de identidade e a busca pelo doce néctar do pertencimento, bem como o medo da crueldade da exclusão. Dessa forma, o sujeito constituído como brasileiro, inserido em um processo histórico-social que fala dele como inferior, desqualificado e malandro, supondo controlar suas vontades, diz o que quer e o que não quer. No entanto, este (não) querer se dá a partir da determinação ideológica e inconsciente. Os sentidos que interpelam esse sujeito deixam marcas no seu inconsciente, as quais se manifestam em seu desejo de pertencer, de fazer parte de outro lugar, outra nacionalidade.

${ }^{84}$ A doçura de estar incluído 
Entretanto, a formação do "nós", a identificação com uma comunidade se dá por oposição aos outros. Assim, criam-se características nacionais e estereótipos sobre os outros países. Rinaldi (1996, p. 88), citando Dumont (1983), expõe que "se não existissem inimigos seria preciso inventá-los". Assim, a ideia de um inimigo, invasor é integrante para que um grupo permaneça unido, sob a ilusão da homogeneidade. É esse sentido do diferente que mantém a ilusão da indivisão interna em oposição à externa e que considera tudo que é externo estrangeiro. Notase o caráter paradoxal desta posição. Ao mesmo tempo em que o medo do estrangeiro é necessário para manter a união da nação, o estrangeiro, quando integrado, misturado ao grupo, ameaça, dada a fragilidade com que são atados estes laços. Abre-se a possibilidade de reconhecimento do estrangeiro que constitui cada sujeito hospedado em sua morada.

\section{A ficção do "nós" e do "eles"}

Então, quem são os "nós"? Quem são os "eles"? Pensando estes termos a partir da exclusão, o "nós" corresponde ao padrão, àqueles que pertencem ao grupo, reconhecem seus semelhantes, bem como sua superioridade, que é projetada sobre "eles". "Eles" são considerados inferiores, os "não-nacionais", aqueles que estão fora do padrão determinado. O "nós" detém o poder do qual o "eles" é excluído, pois representam uma ameaça. Contra esta ameaça cabe qualquer medida: desde o tratamento desumano até a morte. "Eles" são considerados "coisas", negam-lhes o diálogo. Bauman (2013, p. 78) diz que "indivíduos e grupos ou categorias de pessoas têm negada sua subjetividade humana e são reclassificados pura e simplesmente como objetos". O autor diz também que estes indivíduos

tornam-se entidades cuja única relevância (o único aspecto levado em consideração quando se planeja o tratamento que irão receber) para os responsáveis pelas "medidas de segurança" em favor daqueles cuja própria segurança é considerada ou declarada ameaça é a ameaça que eles já constituem, podem constituir ou ser acusado (com plausibilidade) de construir. A negação da subjetividade desqualifica os alvos selecionados como parceiros potenciais ao diálogo; qualquer coisa que possam dizer, 
Os sentidos dos "nós" e dos "eles" nos discursos de migrantes brasileiros no exterior | 203 assim como o que teriam dito se lhe dessem voz, é a priori declarado imaterial, se é que se chega a ouvi-los. (BAUMAN, 2013, p. 78).

O "eles" inferiorizado é colocado em um lugar distante e oculto, desconhecido pelo "nós". O "eles" é necessário para a existência do "nós", no entanto o encontro entre "nós" e "eles" é indesejado, já que obriga o primeiro a entender que o outro existe e não como objeto de sua satisfação, mas como sujeito de desejo "Eles" faz com que o "nós" olhe para o lado, para o lado "feio" da vida, e quer torná-lo culpado por esta desgraça, quer deixá-lo envergonhado de seu sucesso. O "eles" faz lembrar, na sua animalidade, de suas necessidades básicas, faz surgir o não-dito, o inominável e ataca o laço-social como está constituído, põe por terra as ilusões que funcionavam muito bem até então, "sempre há um número demasiado deles. 'Eles' são os sujeitos dos quais deveria haver menos - ou melhor ainda, nenhum". (BAUMAN, 2005, p.47). Rejeitando-se o "eles", ou seja, o estrangeiro, o "nós" assegura-se de não ser contaminado, recusase a questionar suas certezas.

Entretanto, o "nós" é problemático, é impossível identificá-lo, um sujeito pode pertencer ao "nós" em um momento e em outro ser excluído. Mesmo quando se referindo diretamente à estrutura da língua, não identificamos o "nós". Em Benveniste (2006 [1976]), o "nós" não é visto como uma multiplicação do "eu", não se trata de um plural, mas da junção de um "eu" a um "não-eu", amplificado e difuso. O autor (ibidem, diz que

a unicidade e a subjetividade inerentes contradizem a possibilidade de uma pluralização. Se não pode haver vários "eu" concebidos pelo próprio "eu" que fala, é porque "nós" não é uma multiplicação de objetos idênticos mas uma junção entre o "eu" e o "não-eu" [...] Essa junção forma uma totalidade nova e de um tipo totalmente particular, os componentes não se equivalem: em "nós" é sempre "eu" que predomina, uma vez que só há a partir de "eu" e esse "eu" sujeita o elemento "não-eu" pela sua qualidade transcendente. A 
presença do "eu" é constitutiva de "nós". (p. 256).

Neste entendimento, no "nós" o "eu" está sempre incluso e, somado a este, estão outros enunciadores. Essa possibilidade de associar o enunciador a variados referentes sem a obrigação de especificá-los linguisticamente dá ao "nós" uma amplitude referencial muito grande, possibilitando a produção de diferentes tipos de "nós". Em seu estudo sobre os discursos presidenciais, Indursky (2013, p. 82) aponta o "nós" como uma "não pessoa discursiva" pelo fato de designar um conjunto lexical não nomeado. A autora (ibidem, p. 83) diz que "a interlocução discursiva, a não pessoa discursiva corresponde ao referente lexicalmente não especificado ao qual eu se associa para constituir nós". Dada a forma de apresentar referentes tão diversos, ocorre a instauração da indeterminação e da ambiguidade do dizer, possibilitando diferentes efeitos de sentido. Seguem alguns recortes, nos quais podemos observar os efeitos de sentido produzidos pelo "nós".

SD 1 - A única coisa que a gente fica decepcionada, não sei agora morando no México, é quando a gente volta pro Brasil e a gente anda no trânsito e vê que o cara não é educado no trânsito, vê uma mulher jogando lixo no chão, meu filho já diz, olha mãe, a moça jogou lixo no chão... mãe olha, ela passou e viu você falando com o moço e nem pediu licença, são essas coisas que a gente nota, mas que é nosso, é cultural entendeu, e a violência né. (Lúcia - México).

SD 2-O que eu achei é que nós estamos atrasados décadas, ao menos são décadas (muitas batidas gravação não se escuta nada). Da própria universidade, da infraestrutura, do que ela oferece... o transporte foi logo que eu cheguei que eu tive aquele choque... (Marcos - Portugal).

SD 3 - eles ficam muito mais desconfiados porque a Espanha é um país muito mais correto que o nosso... o povo daqui é muito mais correto... claro tem de tudo... mas é um 
Os sentidos dos "nós" e dos "eles" nos discursos de migrantes brasileiros no exterior | 205

povo muito mais correto... o brasileiro tá acostumado com o jeitinho brasileiro e acho que por isso a gente tem tanta corrupção... (Lucas - Espanha).

$\mathrm{Na}$ SD 1, Lúcia ao estranhar algumas atitudes dos brasileiros se coloca numa posição externa ao grupo, ao mesmo tempo em que entende essas características como parte da cultura do brasileiro. Ao usar o pronome "nosso", Lúcia se ampara na coletividade (eu + eles) para tratar dessas práticas como parte da cultura. No entanto, ela se exclui desse "nós" ao não se reconhecer nessas práticas, criando, dessa forma, um efeito de indeterminação; Lúcia identifica-se com o outro espaço no qual se insere. Na sequência seguinte, SD 2, o "nós" refere-se aos órgãos públicos, ao governo que não proporciona o desenvolvimento do país nos moldes daqueles considerados civilizados e modernos. Na SD 3, Lucas usa o pronome "nosso" para se referir ao Brasil, no entanto, produz um distanciamento, "o povo daqui", isto é, "próximo de mim", "com os quais eu convivo", em oposição ao povo de "lá". Dito de outro modo, ele estando entre o povo espanhol, se comporta como um deles. O efeito de sentido de distanciamento em relação aos brasileiros pode ser observado ao dizer "o brasileiro", ou seja, o uso da terceira pessoa.

Nos termos postos por Indursky (2013), quando ocorre o uso da terceira pessoa no lugar do "eu", temos o que ela denominou de a quarta pessoa discursiva, que versa sobre o efeito-sujeito, simulando o apagamento, a ausência deste na materialidade linguística. A autora (ibidem, p. 96) diz que "a substituição de eu ou nós por ele ou se simula o não preenchimento da forma-sujeito, sendo esta mais uma das formas com que o sujeito do discurso relaciona-se com a forma-sujeito que o constitui em sujeito de seu discurso". Simula-se a desvinculação do sujeito. A forma-sujeito aparentemente não preenchida é observada do exterior, o que pode ser verificado nas SDs abaixo:

SD 4 - O nível dos brasileiros que tem aqui é... é bem inferior por exemplo, pessoas formadas, pós graduadas não existe. Só eu e ele aqui. (Helena - USA).

SD 5 - Eu perdi um pouco aquele sistema do brasileiro, que é um sistema muito latino, principalmente do brasileiro de achar que amor é você ter de dar boa-noite, beijinho, 
beijinho, boa-noite, né, tá ali junto colado. (Paulo - Alemanha).

Como se houvesse a possibilidade de se ver de fora, essa forma de representar o sujeito cria um efeito de exterioridade, como se estivesse falando do outro, efeito que não se mantém, já que não ocorre a total dissimulação do sujeito, pois junto ao "ele" está presente o "eu".

Seja por meio do uso da primeira pessoa do plural ou da quarta pessoa, esses discursos comportam um distanciamento destes sujeitos com relação a suas posições de brasileiro. Estes não se identificam com sua cultura, assim como mostram sua admiração pela cultura outra, onde reside seu desejo de pertencimento. Dessa forma, o "eles" aos quais os brasileiros se referem compreende todo mundo: eles que erram, eles que são corruptos - estando este sujeito fora, é, assim, um estrangeiro; da mesma forma, diante da impossibilidade de pertencer a outra cultura, o brasileiro será sempre visto como um estrangeiro.

Resumidamente, os sentidos do "nós" e do "eles" não tem o mesmo referente, mas dada a indeterminação que estes pronomes encerram, ora o "eu" se inclui ora se exclui, conforme esquematizado no quadro seguinte:

\begin{tabular}{|c|c|c|}
\hline \multicolumn{3}{|c|}{ Países Desenvolvidos } \\
\hline $\begin{array}{l}\text { Nós }=\text { eles - eu } \\
\text { (referindo-se aos } \\
\text { brasileiros) }\end{array}$ & $\begin{array}{l}\text { - O "eu" está presente, mas não se } \\
\text { identifica, se isenta da responsabilidade; } \\
\text { - Efeito de distanciamento; } \\
\text { - Olha de um lugar exterior. } \\
\text { - Há um esvaziamento da forma-sujeito. }\end{array}$ & $\begin{array}{l}- \text { Ver SDs } \\
1,2,3 \text {. }\end{array}$ \\
\hline $\begin{array}{l}\text { Eles = eles - eu } \\
\text { (referindo-se aos } \\
\text { brasileiros) }\end{array}$ & $\begin{array}{l}\text { - O "eu" não está presente, se coloca } \\
\text { como exterior ao grupo, não faz parte, } \\
\text { não se responsabiliza; } \\
\text { - Efeito de distanciamento; } \\
\text { - Olha de um lugar exterior; } \\
\text { - Não preenche a forma-sujeito. }\end{array}$ & $\begin{array}{l}\text { - Ver SDs } \\
4 \text { e } 5 \text {. }\end{array}$ \\
\hline $\begin{array}{l}\text { Eles }=\text { eles }+ \text { eu } \\
\text { (referindo-se aos } \\
\text { povos } \\
\text { desenvolvidos) }\end{array}$ & $\begin{array}{l}\text { - Efeito de proximidade; } \\
\text { - Desejo de pertencer. }\end{array}$ & $\begin{array}{c}\text { - Ver SDs } \\
1,2 \\
3 .\end{array}$ \\
\hline
\end{tabular}


Os sentidos dos "nós" e dos "eles" nos discursos de migrantes brasileiros no exterior | 207

Os referentes a que estes pronomes aludem mudam conforme o desejo de pertencimento e a identificação dos sujeitos com o país hospedeiro e com seu país de origem, relação que difere quando tratamos dos países periféricos.

No entanto dada a necessidade de se reconhecer como unidade coerente, de não perder o sentido, ou seja, para dar consistência imaginária ao "eu", como diz Kehl (2001), os sujeitos se colocam como personagem principal num romance, a fim de colocar ordem na fragmentação e na dispersão das identificações. O sujeito migrante necessita de um fio narrativo com começo, meio e fim, do qual é personagem principal e também autor, pois, desgarrado de sua cultura, que lhe conferia a ilusão de um lugar estável, seguro como parte de um todo, sente-se separado dos seus semelhantes e sozinho para escrever sua história. Decorre daí uma angústia ao imaginar-se responsável pelo seu próprio destino.

Esse sentimento com relação ao que é e que aterroriza o sujeito diz respeito ao estranho, o qual compreende "a verdade assustadora do sujeito, que remonta ao que há muito lhe é conhecido e familiar: o desamparo". (FUKS, 2000, p. 109). É em torno deste desamparo que, para a psicanálise, se constitui a posição do sujeito no laço social. Para Freud (1996 [1930]), as possibilidades de sentir a infelicidade e o malestar são maiores do que aquelas que levam à felicidade. As fontes das quais provem o mal-estar são: o corpo, o mundo externo e os relacionamentos humanos, sendo este último o mais penoso.

Quando o sujeito se depara com sua condição de desamparo, impulsionada pelo confronto com a violência, a perda que implica ser estrangeiro faz com que este se volte para sua cultura, devido ao laço social que ela representa, em busca do conforto. O desamparo nas obras de Freud diz respeito às relações traumáticas; dessa forma, quando o sujeito se depara com sua vulnerabilidade, esta remete à angústia da impotência gerada pelo estado de desamparo infantil, decorrente do que Freud denominou "complexo do próximo" (FREUD, 1995 [1976]). O complexo do próximo compreende o laço social com o outro, ou seja, aquele laço que zela, que fornece os cuidados necessários para seu bemestar e que é construído a partir da linguagem. $\mathrm{O}$ laço social submetido à linguagem está também submetido ao Outro ${ }^{85}$.

${ }^{85}$ Nas formulações de Lacan, diferencia-se o "outro" (escrito com o minúsculo), que é do registro do imaginário, do "Outro" (escrito com $\mathrm{O}$ maiúsculo), que é do registro do simbólico. O outro é meu semelhante, aquele com o qual me 
Dito isto, o estrangeiro depara-se com este desamparo, seja por sentir-se excluído da cultura e, com isso, não possuir laços, seja pela impossibilidade de dizer tudo, o que em outra língua serve para reforçar a diferença com relação ao estrangeiro, e não a incompletude própria da língua.

Voltando-se para o estrangeiro, este deseja estabelecer laço social na outra cultura, no entanto, a relação com o outro não é de proteção e amor, mas um laço social a partir de uma violência simbólica que o exclui e o torna alvo de hostilidade, intensificando o mal-estar. As diferenças estabelecidas diante do estrangeiro são predominantemente etnocêntricas. Nesse sentido, é imposto ao estrangeiro uma estigmatização, à qual o sujeito se submete na busca pelo aceite, pelo amor e proteção desse "ser" superior representado pela outra cultura.

Contudo, mesmo quando assimilado por essa cultura, o estrangeiro será sempre aquele que vem de outro lugar, mesmo renegando suas origens. Frente à sua vulnerabilidade, esses sujeitos se voltam para sua cultura, seu país de origem, a fim de tamponar o desamparo, e acabam não se reconhecendo em nenhum lugar, dado que as relações e os elementos que fazem o laço social se reestruturaram e o que era estranho torna-se familiar, bem como o que era familiar agora soa estranho.

Com relação à migração para países periféricos, observemos o relato de Ana abaixo.

SD 6 - Eles mesmos tem preconceito com eles mesmos. Então, por exemplo, assim, você vai ao supermercado, toda vez que você sai do supermercado você tem que mostrar sua nota fiscal e mostrar a sua compra porque apesar de você ter passado pelo caixa, você tem que conferir sua compra. Quando eles veem que você é branco, sabe que você tá vindo aqui no país deles e tá trabalhando, você deve estar trabalhando e tudo, eles já fazem vista grossa. Pegam sua notinha e só

identifico, admiro ou odeio. $\mathrm{O}$ eu se constitui a partir da imagem do outro, que traz em si a imagem esculpida pelos significantes do Outro. Este compreende o lugar dos significantes que marcam o sujeito, sendo acessível somente pelas formações inconscientes. O primeiro a ocupar esse lugar do Outro para a criança é a mãe. 
Os sentidos dos "nós" e dos "eles" nos discursos de migrantes brasileiros no exterior | 209 rasgam ou só assim atrás e nem olham as coisas. (Ana - Nigéria).

Está presente nesta SD a distinção entre os brancos, aqueles que trabalham, têm dinheiro, e os negros como seu oposto. Nesta SD, um sentido possível é que ser da cor branca representa riqueza, permite que Ana não siga as mesmas regras aplicadas aos locais. Riqueza que é fruto do trabalho, como faz questão de dizer ao repetir duas vezes que os brancos estão ali, nesse país, a trabalho. Como um não-dito podemos inferir que não há outra razão para estarem ali, o que justifica certas regalias, já que estão trabalhando e contribuindo com o país.

A questão do preconceito interno, levantada por Ana nessa SD, nos revela sua forma de interpretar o fato de não ter suas sacolas revistadas como os locais. Para ela, essa conduta se traduz em desconfiança dos nigerianos para com os seus iguais. Enríquez (2006) diz que "o mundo atual tende a tornar-se o do crescimento do desprezo, da generalização da desconsideração, do desrespeito, da recusa da diferença a que tem direito todo ser humano". Aquele que não atende aos padrões, assume a culpa para si e reproduz as condições de produção existentes, contribuindo para a manutenção do sistema vigente. $O$ que dá aos estrangeiros, neste lugar, um estatuto de superioridade que impõe uma barreira, uma divisão que busca acentuar a diferença, o que neste caso não é usado para segregar o estrangeiro, mas para manter sua posição de superioridade, o que pode ser considerado nas SDs abaixo:

SD 7 - A gente tem motorista, mas não é luxo. Assim, todos os expatriados, todos os estrangeiros tem motorista. Porque, primeiro porque é uma maneira da empresa cuidar da segurança da família, tendo um local dirigindo, se acontece um acidente, na hora de discutir ali, eles resolvem, a gente não precisa se envolver. (Ana - Nigéria).

SD 8 - Ana: estrangeiro, tem muito estrangeiro, muito branco aqui, principalmente na região que a gente mora. [...] Que é um...um bairro assim, vamos dizer, privilegiado. É um condomínio dentro de um condomínio [...]. Então pra você entrar aqui dentro do nosso bairro tem segurança 
também, mas nesse bairro tem vários condomínios.

Entrevistador: Uhum. E por que, assim, o fato de você ser branca ajuda?

Ana: Porque eles sabem que os brancos têm dinheiro. (Ana - Nigéria).

$\mathrm{Na}$ sequência 7, Ana traz o fato de que os estrangeiros têm motorista. Está presente aqui o não-dito de que os locais não têm acesso a esse benefício, trata-se de uma diferenciação entre os locais e os estrangeiros. O uso da conjunção adversativa "mas" leva a interpretação para outro conjunto de saberes, pois normalmente ter um motorista é artigo de luxo, o que, na situação de Ana, corresponde a cuidar da segurança dos estrangeiros, servindo também como mediador entre os locais e os estrangeiros em caso de necessidade. Chama a atenção o fato de Ana dizer que tendo um motorista "não precisa se envolver". Esse dizer nos leva a confirmar que ela está confortável nesta posição de estrangeira e que não é de seu interesse participar tão de perto desta outra cultura. Para se envolver e resolver alguma situação nesse outro lugar, é preciso invocar regras e sentidos que não fazem parte do seu conjunto de saberes, assim, para Ana, é mais fácil permanecer na posição em que se encontra.

Quanto ao uso do pronome "eles", ainda na SD 7, tem-se a distinção, a separação entre os locais "eles" e os estrangeiros "nós". A cultura pode ser usada como uma ferramenta na construção do outro, afirmando diferenças e legitimando a hierarquização. Cria-se uma espécie de bolha que os protege do apavorante "lá fora" que habita essa cultura. Estabelece-se aí uma relação de poder entre o estrangeiro, aquele que tem dinheiro, e os nigerianos, aqueles que não têm. O termo "expatriado" de que Ana lança mão também marca uma valorização do estrangeiro.

$\mathrm{Na}$ SD 8, constata-se novamente a relação de poder entre os estrangeiros e os locais. Ana ressalta o fato de ter muito estrangeiro na Nigéria pelo uso do advérbio de intensidade "muito", além da repetição da palavra estrangeiro. Esta palavra, nesse recorte, desliza e, além de significar aquele que vem de outro lugar, de outra cultura, se refere também à cor branca da pele. Ser estrangeiro na Nigéria é também ser branco. Essa fronteira estabelecida entre os locais e os estrangeiros pode ser observada também quando Ana nos diz que na região onde mora há muitos estrangeiros, trata-se de um bairro privilegiado, com seguranças que estão ali para manter essa fronteira. Fronteiras imaginadas a partir das diferenças estabelecidas e de onde emana o poder, bem como a 
Os sentidos dos "nós" e dos "eles" nos discursos de migrantes brasileiros no exterior | 211 desigualdade social característica do sistema capitalista, o que dá poder àqueles que detêm o capital financeiro e define aqueles que não o têm como preguiçosos, incompetentes e responsáveis pela sua pobreza. Essa pobreza é, então, legitimada pelo mercado e pela divisão do trabalho.

É válido observar, ainda, a modalização empregada por Ana ao falar do bairro onde mora. Ela diz que é um lugar "vamos dizer" privilegiado. Chama-nos a atenção esse mecanismo de atenuar o sentido de privilegiado, pois podemos entender como "privilegiado" naquele lugar, diante daquela configuração social, mas talvez não em outros. Ana usa duas terceiras pessoas do plural, uma nominada e a outra não. "Eles" x "os brancos". "Eles" corresponde aos negros, e "os brancos" aos estrangeiros. Ela não se inclui, não usa "nós" para se referir aos brancos, apesar de a entrevistadora usar "você" na pergunta. Há uma marca de estrangeiridade em relação a si mesmo, é vergonhoso ter dinheiro em um país tão pobre. Inconscientemente ela não parece admitir dizer "nós temos dinheiro", bem como evita dizer "os negros", referindo-se a estes como "eles". Dessa forma, retomando o dizer de Ana, ser branco ajuda, pois ser branco significa ser estrangeiro, significa ter dinheiro, o que facilita a convivência nesta outra cultura, lhe dá um estatuto de superioridade e até a exime de certas regras.

Os sentidos do "nós" e do "eles" observados nos recortes de uma brasileira que está residindo em um país periférico está resumido no quadro abaixo:

\begin{tabular}{|l|l|l|}
\hline \multicolumn{2}{|l|}{ Países Periféricos } \\
$\begin{array}{l}\text { Nós = eu + eles } \\
\text { (referindo-se aos } \\
\text { estrangeiros) }\end{array}$ & $\begin{array}{l}\bullet \text { Cria um efeito de unidade entre os } \\
\text { estrangeiros } \\
\bullet \text { Não se identificam com a cultura local } \\
\text { e não desejam fazer parte; } \\
\bullet \text { O "eu " se inclui, quer ser estrangeiro } \\
\text { para se diferenciar dos locais. }\end{array}$ & \\
\hline $\begin{array}{l}\text { Eles = eles + eu } \\
\text { (referindo-se aos } \\
\text { estrangeiros) }\end{array}$ & $\begin{array}{l}\bullet \text { O "eu" está presente, ao mesmo tempo } \\
\text { em que dá um efeito de distanciamento, } \\
\text { dada as facilidades e diferença } \\
\text { econômica entre os estrangeiros e os } \\
\text { locais; } \\
\bullet \text { Dá um olhar exterior, mas não deseja } \\
\text { ficar de fora. }\end{array}$ & \\
\hline
\end{tabular}




\begin{tabular}{|l|l|l|}
\hline $\begin{array}{l}\text { Eles = eles - eu } \\
\text { (referindo-se aos } \\
\text { povos periféricos) }\end{array}$ & $\begin{array}{l}\bullet \text { O "eu" não deseja fazer parte; } \\
\bullet \text { Efeito de distanciamento e de isenção } \\
\text { da culpa pela pobreza dos locais; } \\
\bullet \text { Ressalta as diferenças; }\end{array}$ & $\bullet$ Ver SD 6 \\
\hline
\end{tabular}

O desejo de fazer parte da outra cultura e ser confundido com o outro, de fazer parte do "eles", conforme observado nas SDs 1 a 5 , as quais compreendem recortes de participantes que residiam em países desenvolvidos toma outra forma quando em países periféricos. Neste caso, o "nós" cria a ilusão de uma identidade fechada para os estrangeiros que lá estão, ao passo que observa-se um "eles" distante do qual os sujeitos não desejam fazer parte.

\section{Efeito de fechamento}

Lembrando que o significante tomado por Lacan representa a parcela material do signo linguístico, sendo que o significado não tem uma relação fixa com o significante, assim, os significados podem deslizar pela cadeia de significantes do Outro. Esta não relação entre o significante e o significado é observada nesta relação entre os pronomes "nós" e "eles", os quais são ilusoriamente tomados como óbvios e transparentes. No entanto, é no lugar do Outro que se desenrola a cadeia de significantes que determina o significado e o sujeito. Assim, o sujeito constituído em sua língua materna é atravessado por discursos vindos do campo do Outro, os quais atribuem os sentidos sob a ilusão de que sempre estiveram ali - o sujeito os toma como transparentes. Entretanto, ao deparar-se com os significantes vindos de outro lugar, no caso, uma outra língua, o sujeito já não é mais o que acreditava ser, o sujeito, seus desejos e sentidos neste outro lugar dependem do Outro da língua estrangeira. Dessa forma, o sujeito é o resultado da articulação dos significantes da sua língua e da língua outra. Isto vem mexer e desorganizar o que estava inscrito no sujeito em sua primeira língua.

Com base nas nossas análises, vimos que os sentidos dos pronomes "nós" e "eles" mudam de referente de acordo com o lugar que estes sujeitos ocupam no discurso, bem como pela imagem que fazem do lugar outro a partir dos discursos vindos do Outro que o interpelaram/interpelam. Dessa forma, temos que os sujeitos estrangeiros em países desenvolvidos passam a se ver e a se dizer a partir de um lugar inferiorizado - seus desejos assumem a forma desse Outro do qual querem fazer parte, exaltam o que vem do outro estrangeiro e desdenham, 
Os sentidos dos "nós" e dos "eles" nos discursos de migrantes brasileiros no exterior | 213

inferiorizam o que é dito de sua cultura, se excluindo do "nós" enquanto brasileiros e se incluindo no "eles", os locais.

No entanto, quando os sujeitos participantes desta pesquisa se deparam com o Outro representante dos países periféricos, como Angola e Nigéria, assumem o lugar do colonizador, sentindo-se superiores e muitas vezes negando a participação nesta cultura, preferindo ser reconhecidos como estrangeiros, como aqueles que não fazem parte, não pertencem. O "nós" agora é inclusivo e significa um grupo que não faz parte do local, enquanto se coloca também como "eles", mas trata-se de um eles inclusivo quando não quer marcar seu lugar neste grupo estrangeiro dado o fato da diferença social existente. Há também, neste caso, o "eles" de onde o "eu" se exclui totalmente, o "eles" referindo-se aos locais, grupo que estes sujeitos não desejam pertencer.

Podemos destacar que para falar em sentidos precisamos considerar as condições de produção, que, como exposto por Pêcheux (1979), são formações imaginárias, nas quais contam a relação de forças e os discursos que interpelam os sujeitos. Dessa forma, conforme Orlandi (2005), "o dizer não é propriedade particular. As palavras não são só nossas. Elas significam pela história e pela língua. O que é dito em outro lugar também significa nas 'nossas' palavras".

\section{REFERÊNCIAS BIBLIOGRÁFICAS}

ANDERSON B. Comunidades Imaginadas: reflexões sobre a origem e a difusão do nacionalismo. São Paulo: Companhia das Letras, 2008.

BAUMAN, Z. Danos Colaterais: desigualdades sociais numa era global. Rio de Janeiro: Zahar, 2013.

. Ensaios sobre o conceito de cultura. Rio de Janeiro: Ed. Zahar, 2012. . Vidas desperdiçadas. Rio de Janeiro: Ed. Zahar, 2005.

BENVENISTE, E. (1976). Problemas em linguística geral II. Campinas: Pontes Editores, 2006.

ENRIQUEZ, E. O homem do século XXI: sujeito autônomo ou indivíduo descartável. In: RAE - eletrônica, v. 5, n, 1, Art. 10. jan./jun. 2006.

FREUD, S. (1930). Mal-estar na civilização. In: FREUD. O futuro de uma ilusão, o mal-estar na civilização e outros trabalhos. Rio de Janeiro: Imago, 1996. p. 65-174. (Edição standard brasileira das obras psicológicas completas de Sigmund Freud, 21).

. (1976). Projeto de uma Psicologia. Rio de Janeiro: Imago, 1995. 
FUKS, B. Freud e a Judeidade: a vocação do exílio. Rio de janeiro: Zahar, 2000.

INDURSKY, F. A fala dos quartéis e as outras vozes. Campinas: Editora da UNICAMP, 2013.

KEHL, M. R. Minha vida daria um romance. In: BARTUCCI, G. Psicanálise, literatura e estéticas de subjetivação. Rio de Janeiro: Imago, 2001.

ORLANDI. E. Principios e procedimentos. Campinas: Ed. Pontes, 2005.

PÊCHEUX, M. (1983). O Discurso: estrutura ou acontecimento. 6a ed. Campinas: Pontes, 2012. . (1969). Por uma análise automática do discurso (AAD-69). In: GADET, F.; HAK, Tony. Por uma análise automática do discurso: uma introdução à obra de Michel Pêcheux. 4. ed. Campinas: Editora da Unicamp, 2010.

RINALDI, D. Ética da diferença. Rio de Janeiro: EdUERJ: Jorge Zahar ed, 1996.

Recebido em: 20/07/2018

Aceito em: 13/08/2018 